\title{
A REAL OPTIONS APPROACH TO A CLASSICAL CAPACITY EXPANSION PROBLEM
}

\author{
Antonio G. N. Novaes* \\ Departamento de Engenharia de Produção \\ Universidade Federal de Santa Catarina (UFSC) \\ Florianópolis - SC \\ novaes@deps.ufsc.br \\ João Carlos Souza \\ Departamento de Arquitetura \\ Universidade Federal de Santa Catarina (UFSC) \\ Florianópolis - SC \\ jcsouza@arq.ufsc.br \\ * Corresponding author/autor para quem as correspondências devem ser encaminhadas \\ Recebido em 03/2003; aceito em 05/2005 após 2 revisões \\ Received March 2003; accepted May 2005 after 2 revisions
}

\begin{abstract}
Some authors, considering deterministic or stochastic demand patterns and different forecasting formulations, have studied the classical problem of optimally meeting a growing demand for capacity, over an infinite horizon. With this approach, only investment costs discounted with a predefined interest rate are considered in the analysis. Adding other expenditures and revenues, managers usually estimate the discounted cash flow of the project, and assume the organization will follow a predetermined plan when investing, regardless of how events unfold in the future. The real options approach, on the other hand, introduces the possibility of incorporating other decision alternatives in the economic analysis, such as the option of waiting or postponing, abandoning, switching, etc. In this paper we first review the classical capacity expansion models. Then, the concepts and properties of the real options approach, with emphasis on the BlackScholes equation, are briefly discussed. Finally, an application example is presented and discussed.
\end{abstract}

Keywords: capacity expansion models; economic feasibility; real options.

\section{Resumo}

Alguns autores vêm estudando o problema clássico de atender otimamente a demanda por capacidade crescente ao longo de um horizonte infinito, considerando, para isso, formas determinísticas ou estocásticas de expansão da demanda, bem como diferentes formulações de previsão. Com esse enfoque, somente os custos de investimento, descontados a uma taxa predefinida de juros, são considerados na análise. Adicionando outros desembolsos e receitas, os administradores usualmente estimam o fluxo de caixa descontado do projeto, admitindo que a empresa seguirá um plano predeterminado, independentemente da forma como os eventos se desenrolarão no futuro. $\mathrm{O}$ enfoque de opções reais, por outro lado, introduz a possibilidade de incorporar outras alternativas de decisão na análise econômica, tais como a opção de esperar ou postergar, abandonar, trocar, etc. Neste artigo se faz, em primeiro lugar, uma revisão dos modelos clássicos de expansão de capacidade. A seguir, os conceitos e propriedades do enfoque de opções reais, com ênfase na equação de Black-Scholes, são brevemente discutidos. Finalmente é apresentado e discutido um exemplo de aplicação.

Palavras-chave: modelos de expansão de capacidade; viabilidade econômica; opções reais. 


\section{Introduction}

This paper deals with two important topics in the area of finance and economics, namely the capacity expansion problem and the real options approach. Our objective is to make a survey, yet partial, of both topics, stressing the theoretical and practical connections between them. In fact, since the classical models of capacity expansion problems assume a continuous, ever-increasing demand curve and irreversible investments, they do not include all the practical variables usually encountered in present-day investment problems. In a volatile global economy, decisions such as to postpone investments, to contract projects, to shutdown and later restart operations, to close factories, to leave markets (even on a temporary basis), are usually taken today by leading businessmen. The real options approach opens a way to the analyst to correctly evaluate the economic impacts of such actions.

Apart from a review of the related literature, the main contribution of this paper is to show how to introduce the abandoning option into the classical capacity expansion problem. The abandoning option has been frequently used in real life by leading multinational firms. In the automotive industry, for example, one can observe the displacement of entire assembly lines across the borders. For instance, Daimler-Chrysler phased out the production of the Dodge Dakota in Brazil, the Volkswagen Polo, which was produced in Argentina is now produced in Brazil, etc. We intend to show that the treatment of some capacity expansion problems, associated with the real options approach, can yield more realistic and sound solutions.

\subsection{Capacity expansion problems}

Capacity expansion is the process of adding facilities over time in order to satisfy rising demand (Manne, 1961; Freidenfelds, 1980, 1981). Capacity expansion decisions in the business sector generally add up to a massive commitment of capital. The efficient investment of capital depends on making appropriate decisions in individual expansion undertakings. On the other hand, capacity expansion decisions can be improved through the use of Operations Research models. While real capacity expansion problems are very often more complex than the models studied in this paper, a robust, albeit simplified mathematical model, can capture aspects that are important in many applications.

Since the 1960s, quite a number of quantitative studies have been conducted on capacity expansion problems (Manne, 1961; Freidenfelds, 1980, 1981; Luss, 1982, Lieberman, 1989, Higle \& Corrado, 1992; Bean et al., 1992; Li \& Tirupati, 1994; Souza, 1996). Apart from physical additions, the time when expansions occur is of interest for planning purposes. An important characteristic of most capacity problems is the recognition of economies of scale, i.e. large installations usually cost less per produced unit than small ones. But, if the demand level is continuously rising on the long run and backlogging of demand is not permitted, excess capacity will occur (Figure 1). Thus, there is a tradeoff between scale economies and excess capacity cost, leading to a compromised optimal solution. Apart from expansion size and expansion time, other decision variables may be added to the problem, such as the alternative locations of the facilities and/or facility types (Luss, 1982; Fong \& Srinivasan, 1986; Dixit \& Pindyck, 1994; Souza, 1996).

This paper deals with a specific expansion problem, namely the one initially treated by Manne in 1961, and subject to classical extensions by Srinivasan (1967), Freidenfelds (1980, 1981), Lieberman (1989), and Bean et al. (1992). Figure 1 depicts the problem in general terms: given a deterministic or stochastic function of growing demand over time, and 
knowing how capital cost varies as a function of capacity, the objective is to determine the optimal expansion times. Manne (1961), considering a linear demand function, showed that when demand is a Bachelier-Wiener diffusion process in continuous time, the effect of randomness can be equivalently represented by a reduction in the discounting interest rate. Later, Srinivasan (1967) showed that this property is also valid for geometric rate of growth of demand. Freidenfelds (1980), analyzing the case of an arbitrary birth-death demand process, discussed how one can leave the interest rate unchanged and replace the forecasted original demand values by larger quantities, building an "equivalent deterministic demand" model. Bean et al. (1992) generalized the demand processes under which the "equivalent interest rate" approach applies.

This treatment of capacity expansion problems, however, assumes that one continues to place additional facilities in the indefinite future as soon as the facilities are fully utilized. In other words, postponement or abandonment options are not contemplated in such models.

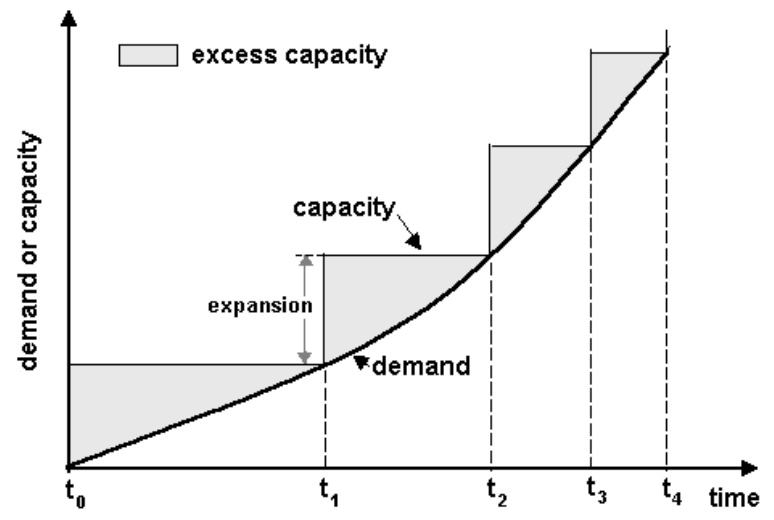

Figure 1 - The capacity expansion process.

\subsection{The real options approach}

A key element at the present stage of the global Economy is the growing flexibility that the world's leading enterprises are inserting in their globalized manufacturing and logistics strategies (Kogut \& Kulatilaka, 1994; Vidal \& Goetschalckx, 1997; Novaes, 2000; Cohen \& Huchzermeier, 2002). Today, large global corporations are increasingly adopting more flexible supply chain and production strategies based on real compound options. Dynamic investment strategies generally include options to wait, to exit, to expand, to switch, and to improve, among others. In general, a firm's ability to anticipate and to respond flexibly to such changes reduces its expected downside risk and thus lowers costs, and/or raises its revenues, which in turn enhances the firm's shareholder value (Cohen \& Huchzermeier, 1999).

Irreversible investments, in our risky world, require a higher level of expected returns because, once the assets are in place, the investment cannot be reversed without losing much of its value. The value of an investment project with options, on the other hand, is usually greater than the one obtained by the traditional approach because the options truncate possible losses at some point. In order to reduce the negative effects, some measures are taken beforehand in order to limit losses to a pre-defined value (Trigeorgis, 1996; Amram 
\& Kulatilaka, 1999; Hull, 1997). Thus, one is able to withstand riskier situations, limiting losses to a bearable, pre-established level.

When solving real options problems the first task is to establish the mathematical frame, a representation of the stochastic processes, the payoff functions, and the decision rules in mathematical terms (Amram \& Kulatilaka, 1999). Next, the solution method is chosen. There are three general solution methods (Amram \& Kulatilaka, 1999):

- The pde approach, in which one solves a partial differential equation (the pde) that equates the change in option value with the change in the value of the tracking portfolio;

- The dynamic programming approach, often associated with binomial models, which lays out possible future outcomes and folds back the value of optimal future strategy;

- The simulation approach, which averages the value of the optimal strategy at the decision date for a great number of possible outcomes (often associated with decision trees).

The book by Trigeorgis (1996) is an important reference on real options. An introductory text is Amram \& Kulatilaka (1999). Other introductory texts of interest are Luehrman, (1995, 1998a, 1998b) \& Edleson (1999). The book by Hull (1997), focusing on the analysis of financial derivatives (stock options, futures, etc.) is an important reference, although it does not deal with real assets (business units, real estate properties, new products, etc.). The book by Copeland \& Antikarov (2001) treats specific real options problems using decision trees. In this paper we adopt the pde approach to calculate the value of an option of abandoning a project after a predefined time horizon.

In section 2 we review the classical capacity expansion models. Then, the concepts and basic properties of the real options approach, with emphasis on the Black-Scholes equation (pde approach), are discussed in section 3. Section 4 establishes the connection between the capacity expansion models and the real options approach. Finally, in section 5, an application example is presented and discussed.

\section{Capacity Expansion Problems with Irreversible Investment Decisions}

We consider the class of problems of optimally planning for the periodic expansion of productive capacity to meet a growing demand for product or service over an infinite horizon. It is assumed throughout this section that the analyzed projects have infinite economic life, with irreversible investment decisions.

\subsection{The deterministic linear model}

The basic Manne model (Manne, 1961) considers the investment decision for a single firm where demand is deterministic and grows at a constant linear rate (Figure 2). Under this approach it is assumed that the facility has an infinite economic life and, whenever demand catches up with the existing capacity, $x$ additional unities of new capacity are installed. Consequently, no backlogs in demand are admitted in this model. The objective is to determine the optimal capacity addition $x$, and the consequent time interval $T$. As a time origin let us take the point $t_{0}$, followed by regeneration points at $t_{0}+T, t_{0}+2 T, t_{0}+3 T$, that represent instants at which the previously existing excess capacity has just been wiped 
out (Figure 2). Note that when the system has reached $t_{0}+T$, the future looks identical with the way it appeared $T$ units of time previously.

The investment that is necessary to add a capacity increment of size $x$, is assumed to be given by a relationship in the form of a power function, with economies of scale

$$
I(x)=k x^{a} \quad(k>0 ; 0<a<1)
$$

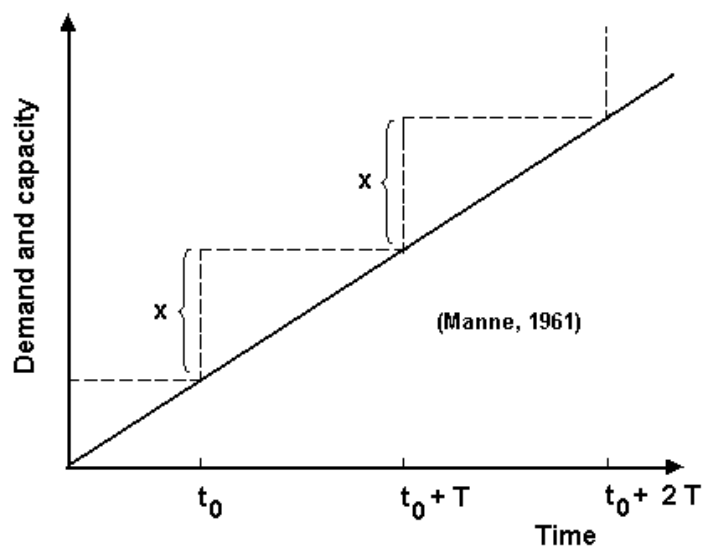

Figure 2 - Growth of demand and capacity over time.

The demand, in this case, is expressed as $p(t)=\mu t$, with $\mu>0$. Admitting that the production cost per unit of product is constant, and since all demand is satisfied (no demand backlogs are permitted), the total operating cost over the project lifetime is also constant. Thus, it does not affect the resulting optimum value of $x$ and therefore it is not included in the model. Let $C(x)$ be a function of $x$ that represents the sum of all discounted future costs looking forward from a point of regeneration. We may write down the following recursive equation (Manne, 1961)

$$
C(x)=k x^{a}+e^{-r t} C(x)
$$

The first term on the right hand side indicates the investment cost incurred at the beginning of the current cycle. The second term represents the sum of all installation costs incurred in subsequent cycles, discounted from the next point of regeneration back to the present with an instantaneous rate $r$, and covering a time span of $t$ years. It follows directly that

$$
C(x)=\frac{k x^{a}}{1-\exp (-r t)}
$$

But, since $t=x / \mu$, expression (3) becomes

$$
C(x)=\frac{k x^{a}}{1-\exp (-r x / \mu)}
$$


The optimal expansion size $\hat{x}$ is obtained by minimizing $C(x)$ with respect to $x$, and the optimal expansion time interval $\hat{t}$ is given by $\hat{t}=\hat{x} / \mu$.

\subsection{Stochastic model with linearly-growing expected demand}

Works such Manne (1961, 1967), Freidenfelds (1980, 1981), and Bean et al. (1992) presented models in which a stochastic demand process is solved by a deterministic equivalent problem in place of the original stochastic model. Such models are based on Brownian motion theory, specifically the Wiener diffusion process in continuous time (Feller, 1957). Suppose a one-dimensional, unrestricted random walk starting at the origin and let $v_{x, n}$ be the probability that the $n^{\text {th }}$ step takes the process to the position $x$. If $r$ among the $n$ steps are directed to the right, and $\ell=n-r$ are directed to the left, the total displacement is $r-(n-r)=2 r-n$ units. This displacement can equal $x$ only if $\mathrm{n}$ and $x$ are either both even or both odd. If this condition is respected, then

$$
r=\frac{x+n}{2} \quad \text { and } \quad \ell=n-r=\frac{n-x}{2}
$$

Out of $n$ steps $r$ can be selected in $\left(\begin{array}{l}n \\ r\end{array}\right)$ ways, and therefore

$$
v_{x, n}=\left(\begin{array}{l}
n \\
r
\end{array}\right) p^{r} q^{\ell},
$$

where $p$ is the probability that one step is directed to the right, and $q=1-p$ is the probability that it is directed to the left. Let us now change the unit of length so that each step has length $\Delta x$, and suppose that the time between any two consecutive steps is $\Delta t$. During time $t$ the process performs about $t / \Delta t$ jumps, and a displacement $x$ is now equivalent to $x / \Delta x$ units. Only multiples of $\Delta x$ and $\Delta t$ represent meaningful coordinates, but in the limit $\Delta x \rightarrow 0, \Delta t \rightarrow 0$ every displacement and all times become possible. However, one must not expect sensible results if $\Delta x$ and $\Delta t$ approach zero in an arbitrary manner, for the maximum possible displacement in time $t$ amounts to $t \Delta x / \Delta t$, so that in the limit no motion exists if $\Delta x / \Delta t \rightarrow 0$. Physically speaking, one must keep the $x$ and $t$ scales in an appropriate ratio or the process will degenerate in the limit, the variances tending to zero or infinity. To find the proper ratio one considers the total displacement during time $t$, which is the sum of about $t / \Delta t$ mutually independent random variables. The mean and the variance of the resulting displacement $x$ is (Feller, 1957)

$$
\begin{aligned}
& E(x)=t(p-q)(\Delta x / \Delta t) \\
& \operatorname{Var}(x)=4 t p q \frac{(\Delta x)^{2}}{\Delta t}
\end{aligned}
$$

The finiteness of the variance requires that $(\Delta x)^{2} / \Delta t$ should remain bounded. The finiteness of the mean implies that $p-q$ must be of the order of magnitude of $\Delta x$. These requirements are satisfied by putting (Feller, 1957; Manne, 1961) 


$$
\frac{(\Delta x)^{2}}{\Delta t}=\sigma^{2}, \quad p=\frac{1}{2}+\frac{\mu}{2 \sigma^{2}} \Delta x, \quad q=\frac{1}{2}-\frac{\mu}{2 \sigma^{2}} \Delta x,
$$

where $\sigma$ and $\mu$ are constants. The norm (9) is used to pass to the limit $\Delta x \rightarrow 0, \Delta t \rightarrow 0$. The total displacement at time $t \approx n \Delta t$ is determined by $n$ Bernoulli trials, and therefore the limiting form of $v_{x, n}$ is given by the normal distribution. The mean of the resulting normal distribution is obtained by combining expressions (7) and (9), and simplifying

$$
E[x(t)]=t(p-q)(\Delta x / \Delta t)=\mu t
$$

The variance is obtained similarly, combining expressions (8) and (9)

$$
\operatorname{Var}[x(t)]=4 \operatorname{tp} q \frac{(\Delta x)^{2}}{\Delta t}=\sigma^{2} t-\frac{\mu^{2}(\Delta x)^{2}}{\sigma^{2}} t,
$$

but, since $\Delta x \rightarrow 0$

$$
\operatorname{Var}[x(t)] \rightarrow \sigma^{2} t
$$

We are interested in determining the instant $t$ where demand first exceeds the installed capacity. At that time additional facilities will be supplied. In stochastic process terminology, we seek the first passage time at point $x$, with probability $u(t, x)$. The following difference equation applies (Manne, 1961)

$$
u(t+\Delta t, x)=p u(t, x-\Delta x)+q u(t, x+\Delta x)
$$

Expanding expression (12) according to Taylor' theorem up to terms of second order

$$
\Delta t \frac{\partial u(t, x)}{\partial t}=(q-p) \Delta x \frac{\partial u(t, x)}{\partial x}+\frac{(\Delta x)^{2}}{2} \frac{\partial^{2} u(t, x)}{\partial x^{2}},
$$

or dividing both sides by $\Delta t$, one gets

$$
\frac{\partial u(t, x)}{\partial t}=(q-p) \frac{\Delta x}{\Delta t} \frac{\partial u(t, x)}{\partial x}+\frac{(\Delta x)^{2}}{2 \Delta t} \frac{\partial^{2} u(t, x)}{\partial x^{2}}
$$

From (9) we get $-\mu=(q-p)(\Delta x / \Delta t)$ and $\sigma^{2} / 2=(\Delta x)^{2} /(2 \Delta t)$. Substituting into (13) one has

$$
\frac{\partial u(t, x)}{\partial t}=-\mu \frac{\partial u(t, x)}{\partial x}+\frac{\sigma^{2}}{2} \frac{\partial^{2} u(t, x)}{\partial x^{2}}
$$

The Laplace transform of $u(t, x)$, indicated by $\bar{U}(s, x)$, is

$$
\bar{U}(s, x)=\int_{t=0}^{\infty} u(t, x) e^{-s t} d t
$$

where $s$ is the transform variable. Taking the Laplace transform of (14)

$$
s \bar{U}(s, x)=-\mu \frac{\partial \bar{U}(s, x)}{\partial x}+\frac{\sigma^{2}}{2} \frac{\partial^{2} \bar{U}(s, x)}{\partial x^{2}},
$$


which is rearranged as follows

$$
\frac{\partial^{2} \bar{U}(s, x)}{\partial x^{2}}-\frac{2 \mu}{\sigma^{2}} \frac{\partial \bar{U}(s, x)}{\partial x}-\frac{2 s}{\sigma^{2}} \bar{U}(s, x)=0
$$

The characteristic equation of (17) has two real roots

$$
\lambda_{1}=\frac{\mu}{\sigma^{2}}\left[1+\sqrt{1+\frac{2 s \sigma^{2}}{\mu^{2}}}\right], \quad \lambda_{2}=\frac{\mu}{\sigma^{2}}\left[1-\sqrt{1+\frac{2 s \sigma^{2}}{\mu^{2}}}\right] .
$$

The general solution for the differential equation (17) is of the form

$$
\bar{U}(s, x)=A(s) e^{\lambda_{1} x}+B(s) e^{\lambda_{2} x},
$$

where $A(s)$ and $B(s)$ are constants whose values depend upon the boundary conditions, which are (Manne, 1961): (a) $\bar{U}(s, x)$ must lie between zero and unit, for $s \geq 0$; (b) since $u(t, x)$ is a probability density function over $\mathrm{t}$, one has $\int_{t=0}^{\infty} u(t, x) d t=1$ and consequently, putting $s=0$ into (15), one gets the second boundary condition $\bar{U}(0, x)=1$. These conditions lead to $A(s)=0$ and $B(s)=1$, yielding

$$
\bar{U}(s, x)=e^{\lambda_{2} x}
$$

Now, since $x$ is a random variable, the probabilistic equivalent of (2) is

$$
C(x)=k x^{a}+\int_{0}^{\infty} u(t, x) e^{-r t} C(x) d t,
$$

but $\int_{0}^{\infty} u(t, x) e^{-r t} d t=\bar{U}(r, x)$, and then

$$
C(x)=k x^{a}+\bar{U}(r, x) C(x),
$$

which yields

$$
C(x)=\frac{k x^{a}}{1-\bar{U}(r, x)}=\frac{k x^{a}}{1-\exp \left(\lambda_{2} x\right)},
$$

Again, the optimal expansion size $\hat{x}$ is obtained by minimizing $C(x)$ with respect to $x$, and the optimal expansion time interval $\hat{t}$ is given by $\hat{t}=\hat{x} / \mu$.

\subsection{More general stochastic demand models}

\subsubsection{Equivalent deterministic model for linearly-increasing expected demand}

In order to study more general stochastic demand models, Freidenfelds (1980) wrote the Laplace transform (20) in a somewhat different form. He introduced an equivalent growth rate $g$, putting 


$$
\bar{U}(s, x)=\exp \left(-\frac{s x}{g}\right)=\exp \left(\lambda_{2} x\right)
$$

which, combined with (18) with $s=r$, yields

$$
g=\left(\mu+\sqrt{\mu^{2}+2 r \sigma^{2}}\right) / 2
$$

Expression (23) is accordingly rewritten

$$
C(x)=\frac{k x^{a}}{1-\exp (-r x / g)}
$$

Comparing expressions (4) and (26) one deducts that the stochastic model with linearlyincreasing expected demand can be solved with the equivalent deterministic model by making a simple substitution in equation (4). This motivates us to define the equivalent deterministic demand process by creating the following equivalent interest rate (Freidenfelds, 1980)

$$
r^{*}=\mu r / g
$$

\subsubsection{Generalization of the equivalent deterministic solution approach}

Assume now that $D(t)$, the demand for product or service, is a continuous stochastic process $\{D(t), t \geq 0\}$. One is interested in selecting a sequence of capacity expansions to satisfy the demand $D(t)$ over an infinite horizon at minimum expected discounted cost using interest rate $r$. A continuous state stochastic process $\{D(t), t \geq 0\}$ is said to be transformed Brownian motion with underlying rate $\mu$ and variance $\sigma^{2}$ if there exists a nonnegative increasing deterministic transformation $h$ such that $D(t)=h(d(t))$, where $\{d(t), t \geq 0\}$ is a linear Brownian motion with drift $\mu>0$ and variance $\sigma^{2}>0$ (Bean et al., 1992). The function $h$ is referred to as the transforming function.

Bean et al. (1992) demonstrated that if $\{D(t), t \geq 0\}$ is transformed Brownian motion as defined above, the equivalent interest rate $r^{*}$ to be used in the equivalent deterministic problem is given by

$$
r^{*}=\left(\frac{\mu}{\sigma}\right)^{2}\left(\sqrt{1+2 r\left(\frac{\sigma}{\mu}\right)^{2}}-1\right)
$$

Bean et al. (1992) demonstrated that every optimal capacity expansion sequence for the deterministic problem with demand $D(t)=h(d(t))$, in which all costs are continuously discounted using the interest rate $r^{*}$, is optimal for the stochastic equivalent problem. In other words, equation (4) is written as

$$
C(y)=\frac{k y^{a}}{1-\exp \left(-r^{*} y / \mu\right)},
$$


with $y=h(x)$. It can be shown that, for $h(t)=\mu t$ (i.e. linearly increasing expected demand), the equivalent interest rate derived by Freidenfelds (1980) and defined in equation (27) yields the same result as the one obtained through equation (29). Bean et al. (1992) showed that $r^{*} \leq r$. Therefore, the qualitative effect of demand uncertainty is summarized by a drop in the effective rate of interest. Consequently one would optimally install larger facilities than one would in the absence of demand uncertainty (Bean et al., 1992).

Srinivasan (1967) analyzed the deterministic problem with geometric rate of growth of demand with a somewhat different approach. He further showed that the optimal policy is to install facilities in equal-time intervals between installation epochs.

\subsubsection{First passage time}

The Laplace transform of the probability distribution $u(t, x)$, given by equation (20), allows us to compute the expected value and the variance of the first passage time to the level $x$. One has (Souza, 1996)

$$
\begin{gathered}
E[t]=-\left.\frac{\partial \bar{U}(s, x)}{\partial s}\right|_{s=0}=\frac{x}{\mu}, \\
\text { and } \operatorname{var}[t]=\left.\frac{\partial^{2} \bar{U}(s, x)}{\partial s^{2}}\right|_{s=0}-\{\mathrm{E}[\mathrm{t}]\}^{2}=\frac{x \sigma^{2}}{\mu^{3}}=\left(\frac{\sigma}{\mu}\right)^{2} E[t]
\end{gathered}
$$

For the general case with $P(t)=h(p(t))$ one has (Souza, 1996)

$$
\begin{array}{r}
E[t]=\frac{h(x)}{\mu}, \text { and } \\
\text { and } \operatorname{var}[t]=\left(\frac{\sigma}{\mu}\right)^{2} E[t]
\end{array}
$$

\section{Economic Evaluation with the Real Options Approach}

\subsection{Flexibility, globalization and the real options approach}

A key element at the present stage of the global Economy is the growing flexibility that the world's leading enterprises are inserting in their manufacturing and logistics strategies (Verter \& Dincer, 1995; Vidal \& Goerschalckx, 1997; Kogut \& Kulatilaka, 1994; Novaes, 2000). The emphasis on flexibility is due to fierce business competition, with firms struggling to increase their market share and their margins. The environment where global firms operate is fuzzy and full of uncertainties, with exchange-rate variations and oscillating demand levels.

Today, large global corporations are increasingly adopting supply chain and production strategies based on real compound options (Cohen \& Huchzermeier, 1999, 2002). Operational flexibility through global coordination of value-adding activities and the timing of investment decisions can enhance the firm's shareholder value significantly. Dynamic investment strategies generally include options to wait, to exit, to expand, to switch, and to 
improve, among others. And the literature on real options has demonstrated that in most cases the option value of operational flexibility is greater than zero (Dixit \& Pindyck, 1994). In general, a firm's ability to anticipate and to respond flexibly to such changes reduces its expected downside risk and thus lowers costs, and/or raises its revenues (Cohen \& Huchzermeier, 1999).

Managers who make strategic investment decisions in the globalized economy often view uncertainty as a negative and costly variable. But they also recognize that many valuable opportunities come with a great deal of uncertainty. Thus, in order to obtain good economic and financial results, they have to proactively expand the set of strategic decision alternatives before them, aggregating project value and risk. Once our way of thinking includes uncertainty, the decision-making framework unfolds, leading to a broader range of investment opportunities. The option approach is a new form of evaluating investment alternatives, providing consistent project valuations, and making possible comparisons of diverse strategic opportunities (Luehrman, 1995, 1998; Edleson, 1999; Amram \& Kulatilaka, 1999; Bengtsson, 1999; Copeland \& Antikarov, 2001).

In general terms, an option is the right, but not an obligation, to take an action in the future. Options are valuable when there is uncertainty. For example, a call option contract traded on the financial exchanges gives the buyer the opportunity to buy a stock at a certain date and will be exercised only if the price of the stock on that date exceeds the previously specified price. When the transaction involves the right to buy an underlying asset at a fixed price on a future date, one has a call option. Conversely, a put option occurs when it involves the right to sell the underlying asset at a fixed price. A European option is exercised at a predefined date; conversely, an American option may be exercised at any date prior to the predetermined deadline.

In addition to financial options (stock options, forwards, and future contracts), that were first studied by analysts and researchers, the term real options refer to the extension of financial option theory to real, no financial assets (Amran \& Kulatilaka, 1999). Real options amplify management's flexibility and ability to respond to external developments over time. The main categories of real options are: (1) growth options, (2) the option to expand scale, (3) timing (the option to wait), (4) the option to switch inputs, outputs, or processes, (5) the option to reduce scale (contract), and (6) abandonment options (Cohen \& Huchzermeier, 1999). Abandonment options are important in capital-intensive industries where management would like to have the flexibility to capture some resale value for assets if their in-use value to the company falls (Edleson, 1999). This is the kind of real option that will be applied and discussed in this paper.

\subsection{The Wiener and Ito processes}

As mentioned in the introduction, there are three general methods to solve real options problems: the partial differential equation (pde) approach, the dynamic programming approach, and the simulation approach. In the sequel we will analyze the first method, more specifically the Black and Scholes equation, which is based on the Wiener-Ito process.

A Wiener process is a particular Markov process, called Brownian motion, originally used in Physics to describe the movement of a particle subject to small sequential perturbations (Feller, 1957; Hull, 1997). The Wiener diffusion process has been already applied to analyze demand variations associated with stochastic modeling in Section 2.2 of this paper. Let $z$ be a 
variable that follows a Wiener process, and let $d z$ be an infinitesimal variation of $z$ in the interval $d t$. The two basic properties of the Wiener process are:

a) $d z$ is related to $d t$ according to

$$
d z=\varepsilon \sqrt{d t},
$$

where $\varepsilon$ is a normally distributed random variable with zero mean and standard deviation equal to unity (normalized distribution);

b) the values of $d z$, for any two different instants of time, are statistically independent.

The Wiener process with drift for a variable $x$ is defined in terms of $d t$ and $d z$, as follows

$$
d x=a d t+b d z,
$$

where $a$ and $b$ are constants. When $a$ and $b$ depend on the values of $t$ and $x$, one has the Ito process

$$
d x=a(x, t) d t+b(x, t) d z
$$

Growth models of money-related variables generally presuppose that deviations are not linear, being expressed as a proportion (a percentage) of the asset value. Let $S$ be a moneyrelated variable for which we want to study the variation $d S / S$. One writes the corresponding Ito process equation

$$
\frac{d S}{S}=\mu d t+\sigma d z \quad \text { or } \quad d S=\mu S d t+\sigma S d z
$$

where $\mu S$ is the expected instantaneous deviation rate and $\sigma^{2} S^{2}$ is the corresponding variance rate. When (37) is observed, the value $S$ of the asset follows a log-normal process (Hull, 1997). Departing from equation (37), and considering a generic function $G$ of $S$ and $t$, Ito derived a lemma that bears his name (Hull, 1997)

$$
d G=\left(\frac{\partial G}{\partial S} \mu S+\frac{\partial G}{\partial t}+\frac{1}{2} \frac{\partial^{2} G}{\partial S^{2}} \sigma^{2} S^{2}\right) d t+\frac{\partial G}{\partial S} \sigma S d z
$$

It is important to note that $G$ also follows an Ito process, with a drift rate of $\frac{\partial G}{\partial S} \mu S+\frac{\partial G}{\partial t}+\frac{1}{2} \frac{\partial^{2} G}{\partial S^{2}} \sigma^{2} S^{2}$ and a variance rate of $\left(\frac{\partial G}{\partial S}\right)^{2} \sigma^{2} S^{2}$.

\subsection{Uncertainty, risk and volatility}

Uncertainty is the randomness observed in the external environment. Managers cannot change its level. The adverse, possible economic consequences of a firm's exposure to external uncertainty is risk (Amran \& Kulatilaka, 1999). Volatility, on the other hand, is a numerical measure of uncertainty. Suppose that the actual growth rate of a certain variable under consideration is a random variable. Its standard deviation $\sigma$, expressed in annual terms, is called volatility, and reflects the range of uncertainty over the growth rate. 
The integration of (37), making $\sigma=0$, yields the expected growth function of $S$

$$
S(t)=S_{0} \exp (\mu t),
$$

where $S_{0}$ is the value of $S$ at $t=0$. Considering the process evolution from instant $t-1$ to instant $t$, one has

$$
S(t)=S(t-1) \exp \left(u_{t}\right),
$$

leading to

$$
u_{t}=\ln [S(t)]-\ln [S(t-1)]
$$

Taking a time series containing $n$ values of $u_{t}$, one estimates its mean and standard deviation. The time $t$ is usually measured in days, weeks, or months, so we have to compute the equivalent annual standard deviation in order to evaluate the volatility $\sigma$ to be used in the calculations (Hull, 1997).

\subsection{The Black-Scholes equation}

Let $S$ be the value of an asset such that the variable $d S / S$ follows the Ito process given by (37). Suppose $f$ is the price of an option or another derivative of the asset under consideration, with its value depending on $S$ and $t$. Departing from the Ito's lemma, putting $G=f$ in (38), and taking the discrete versions of relations (37) and (38), one has (Hull, 1997)

$$
\begin{gathered}
\Delta S=\mu S \Delta t+\sigma S \Delta \mathrm{z} \text { and } \\
\Delta f=\left(\frac{\partial f}{\partial S} \mu S+\frac{\partial f}{\partial t}+\frac{1}{2} \frac{\partial^{2} f}{\partial S^{2}} \sigma^{2} S^{2}\right) \Delta t+\frac{\partial f}{\partial S} \sigma S \Delta z,
\end{gathered}
$$

where $S$ represents a stock and $f$ a derivative on $S$. Finding an appropriate portfolio of the stock and the derivative, it is possible to eliminate the Wiener process $\Delta z$. Let $\pi$ be the value of this equivalent portfolio. Its variation is (Hull, 1997)

$$
\Delta \pi=-\Delta f+\frac{\partial f}{\partial S} \Delta S
$$

Putting (42) and (43) into (44), one gets

$$
\left(-\frac{\partial f}{\partial t}-\frac{1}{2} \frac{\partial^{2} f}{\partial S^{2}} \sigma^{2} S^{2}\right) \Delta t=r\left(-f+\frac{\partial f}{\partial S}\right) \Delta t
$$

We observe that the resulting equation (45) does not contain $\Delta z$, which is responsible for the risk variation in the Wiener-Ito process, as indicated in equation (37). This is an important result because it indicates that the value $\pi$ of the portfolio is not subject to risk at time $t+\Delta t$, and consequently the portfolio will instantly yield a risk-free rate of return $r_{f}$ (Hull, 1997). Thus, $\Delta \pi$ can be simply expressed as

$$
\Delta \pi=r_{f} \pi \Delta t .
$$


Putting (44) and (45) into (46), one gets

$$
\left(-\frac{\partial f}{\partial t}-\frac{1}{2} \frac{\partial^{2} f}{\partial S^{2}} \sigma^{2} S^{2}\right) \Delta t=r_{f}\left(-f+\frac{\partial f}{\partial S}\right) \Delta t,
$$

which leads, after simplifications, to the Black and Scholes differential equation (Hull, 1997; Amram \& Kulatilaka, 1999)

$$
\frac{\partial f}{\partial t}+r S \frac{\partial f}{\partial S}+\frac{1}{2} \sigma^{2} S^{2} \frac{\partial^{2} f}{\partial S^{2}}=r_{f} f
$$

where:

$S$ - the present value of the asset;

$f$ - the price of the derivative, which is a function of $S, t, r$ and $\sigma$;

$r_{f}$ - the risk-free interest rate.

It is interesting to observe that the Black-Scholes equation separates the risk-free return on the investment, represented by $r_{f}$, from the risk generated by the market variability, represented by the volatility $\sigma$. In the sequel, we will see how the Black-Scholes concepts compare with the traditional discounted cash flow (DCF) method to evaluate investment projects. For a European put option, which will be used in the application, the boundary condition to solve (48) is (Hull, 1997)

$$
f=\max \{X-S, 0\} \text { for } t=T,
$$

where $X$ is the exercise price and $T$ is the time to expiration. The integration of (48), subject to (49), yields

$$
f=X \exp \left(-r_{f} T\right) N\left\{-d_{2}\right\}-S N\left\{-d_{1}\right\}
$$

where $N\{w\}$ is the integral of the standard normal distribution at point $w$, with

$$
d_{1}=\left[\ln \left(\frac{S}{X}\right)+\left(r_{f}+0.5 \sigma^{2}\right) T\right]\left[\frac{1}{\sigma \sqrt{T}}\right]
$$

and

$$
d_{2}=d_{1}-\sigma \sqrt{T}
$$

The value of a European call option is similarly determined assuming the appropriate boundary condition (Hull, 1997). The Black-Scholes equation gives a way of computing the economic impact, on the project under study, of real options as, for example, the exiting or abandonment option. Many authors have developed variations of the Black-Scholes equation in order to solve specific financial problems (Margrabe, 1978; Myers \& Majd, 1990; Hull, 1997). In particular, Margrabe (1978) developed a special model to evaluate an abandonment option. Suppose a firm is evaluating an investment proposal at time zero. At time $T$, the firm has the option to abandon or retain the project. If the project is abandoned, the cash flow realized by the firm is $X$. On the other hand, if the project is retained, the value realized by the firm at that time is $S$. Admitting that both $X$ and $S$ are lognormally distributed (Schnabel, 1992), Margrabe's exchange option pricing model is (Margrabe, 1978)

$$
f=X_{0} N\left(d_{1}\right)-S_{0} N\left(d_{2}\right),
$$


where

$$
d_{1}=\left[\ln \left(\frac{X_{0}}{S_{0}}\right)+0.5 \sigma^{2} T\right]\left[\frac{1}{\sigma \sqrt{T}}\right] \text { and } d_{2}=d_{1}-\sigma \sqrt{T},
$$

and where $X_{0}$ is the discounted value of the project asset's abandonment value, $S_{0}$ is the discounted value of the project's value-in-use, and $N(\cdot)$ is the cumulative unit normal probability distribution (Schnabel, 1992). Here $f$ is a call option on the abandonment value, and a put option on the project's value-in-use (Margrabe, 1978; Schnabel, 1992). Margrabe (1978) shows that the option (53) is worth more alive than dead, which implies that its holder will not exercise it until the last possible moment. In other words, the option $f$ is of a European type.

Margrabe (1978) decomposes $\sigma^{2}$ into two components, $\sigma_{X}^{2}$ and $\sigma_{S}^{2}$, according to the following formula

$$
\sigma^{2}=\sigma_{X}^{2}-2 \sigma_{X} \sigma_{S} \rho+\sigma_{S}^{2},
$$

where $\sigma_{X}$ is the coefficient of variation associated with the abandonment value of the project, $\sigma_{S}$ is the coefficient of variation associated with the value-in-use of the project, and $\rho$ is the correlation between $X$ and $S$ (Margrabe, 1978; Schnabel, 1992). If $\sigma_{X}=0$, Margrabe's model reduces itself to the Black and Scholes original formulation (Margrabe, 1978). Since in practical applications the abandonment value is not deterministic (i.e, $\sigma_{X}>0$ ), the use of Margrabe's model is of advantage when analyzing abandonment options.

\section{Real Options and the Discounted Cash-Flow Method}

The financial tool traditionally used to estimate the economic value of a project - discounted cash flow (DCF) - assumes that the enterprise will follow a predetermined plan when investing, regardless of how events unfold in the future. By computing the net present value of a project (NPV), the corporation will increase its own value by making the investment when the NPV is positive. Otherwise, the corporation should not make the investment. NPV calculation presupposes that unknown risky future cash flows be summarized by their expected values, discounted to the present at a risk-adjusted discount rate, leading to a single, simple measure for decision making. The net present value is given by

$$
N P V=-I_{0}+\sum_{t=1}^{T} \frac{R_{t}-E_{t}}{(1+r)^{t}}+\frac{S V_{T}}{(1+r)^{T}},
$$

where $I_{0}$ is the investment at time zero, $r$ is the annual interest rate, $T$ is the duration of the project, $R_{t}$ is the sum of all revenues at year $t, E_{t}$ is the sum of all expenditures at year $t$, and $S V_{T}$ is the salvage value of the project at time $T$. The project is economically feasible if $N P V>0$.

One of the questions about the validity of this method, when applied to real-world problems, is how to incorporate risk in the evaluation of a project. One way to do this is to use the Capital Asset Pricing Model (CAPM) developed by Sharpe and Lintner forty years ago 
(Campbell et al., 1997). The CAPM was developed, at least in part, to explain the differences in risk premium across assets. According to the CAPM, these differences are due to differences in the risk of the returns on the assets (Jagannathan \& McGrattan, 1995). Let $r_{f}$ be the rate of return on the risk-free asset. Consider, next, a portfolio involving all types of assets traded in the economy. Let $r_{M}$ be the average rate of return of such a portfolio. The risk assets contemplated by the investor have returns that are not known with certainty at the time the investments are made. The CAPM asserts that the correct measure of riskness of the asset $i$ is a coefficient called beta. The basic equation is

$$
r_{i}=r_{f}+\left(r_{M}-r_{f}\right) \beta_{i},
$$

where $r_{i}$ is the expected return of the asset $i, r_{f}$ is the risk-free rate of return, and $\beta_{i}$ is a measure of the relative risk of asset $i$ with reference to the whole portfolio, given by (Campbell et al., 1997)

$$
\beta_{i}=\frac{\operatorname{Cov}\left[r_{i}, r_{M}\right]}{\operatorname{Var}\left[r_{M}\right]} .
$$

The risk-free return is the interest rate earned by entities that are entirely creditworthy during the period of a loan, such as the rates paid by the US Treasury and the rates of EU's government bonds. Many large companies have incorporated into their capital budgeting process the CAPM, although it is not free of some academic criticism (Jagannathan \& McGrattan, 1995). But the model is simple and robust, and as Jagannathan \& McGrattan (1995) have shown, it is useful in many practical applications.

A drawback of the classical models of capacity expansion is the duration assumed for the project. In fact, they assume a continuous, ever-increasing demand curve. In other words, it is assumed that the project lasts forever, with irreversible investment decisions. The investor may admit the hypothesis of abandoning the project after a period of $T$ years, selling the asset for a discounted salvage value $S V_{T}$, as in equation (56), but the decision to continue or to abandon the project is an all or nothing initiative to be taken at time zero.

The real options approach, on the other hand, treats this question in a different manner. If market conditions turn out to be poor without any chance of recovery after a certain period of time, the management has an option to abandon the project and sell it for salvage value (Trigeorgis, 1996). The management can use this option as an insurance against failure in the market. The perspective of abandoning the project at time $T$ can be seen as analogous to issuing a put option at instant zero, to be exerted at time $T$ (Trigeorgis, 1996). Suppose an industry has invested an amount $I_{0}$ in a new project, at time zero, and suppose the firm is contemplating two alternatives: (a) abandoning the project after $T$ years for its salvage value; (b) further proceeding with the project. Adopting alternative (a), the exercise price would be the present value of the salvage value (Schnabel, 1992)

$$
X_{0}=\sum_{t=1}^{T} \frac{R_{t}-E_{t}}{(1+r)^{t}}+\frac{S V_{t}}{(1+r)^{T}}
$$

At $t=T$ the firm may proceed further with the project. In case the project is retained, the discounted value realized by the firm at time $T$ is $S_{0}$, the project's value-in-use, which is equal to the present value of the cash flows after year $T$ (Schnabel, 1992) 


$$
S_{0}=\sum_{t=T+1}^{\infty} \frac{R_{t}-E_{t}}{(1+r)^{t}}-\sum_{t=T}^{\infty} \frac{I_{t}}{(1+r)^{t}}
$$

where the $I_{t}$ are the periodical investments necessary to increase production capacity.

An important conceptual difference between the $D C F$ method and the real options approach is the meaning of the salvage value at the end of period $T$. The value $P$ of the put-call option, given by (53), reflects what the market is presently willing to pay to have the right to buy the asset for a price $X$ at the end of period $T$. Thus, $P$ it is not merely a discounted value, but rather a current market evaluation of the future value of the asset. The modified present value of the project is the sum of the $N P V$ given by (56) and the value $P$ of the put-call option, given by (53)

$$
N P V^{\prime}=\mathrm{NPV}+P
$$

which, if positive, will indicate that the project is economically feasible, at least for a period of $T$ years.

\section{An Application}

When applying traditional capacity expansion models, associated with classical economic feasibility analysis methods, one gets unfeasible solutions sometimes. This can happen because a good part of the forecasted variables (sales, for example) present a high degree of variability. As a consequence, investment decisions must incorporate other possible actions and outcomes, and the economic analysis methodology must be changed accordingly.

Our hypothetical example involves a large global automaker that is planning to build a plant in Brazil to produce small cars. Performing regression analysis on the data extracted from the Statistical Yearbook of the Brazilian Automotive Industry (Anfavea, 2002), the industry defined the following project framework:

- current local market: 1,300,000 automobile sales per year;

- company expected market share: $10 \%$;

- market average expansion rate: $\alpha=6 \%$ per year;

- demand volatility, expressed by the coefficient of variation $(\sigma / \mu)$ : $C V=0.34$ (taken from the time series indicated in Figure 3).

Demand is expressed in cars per year. Total investment is a function of plant capacity (cars/year), and is given by

$$
I(x)=0.436 x^{0.65} \quad \text { (million US \$). }
$$

The production target for the firm under analysis is $D_{0}=0.10 \times 1,300,000=130,000$ cars/year at $t=0$. The linear annual expansion rate at time zero is $\mu=\alpha \times D_{0}=7,800$ cars, and $\sigma=C V \times \mu=0.34 \times 7,800=2,652$.

In order to compute the optimal expansion period, we analyze four different models as indicated in Table 1. For the deterministic linear model (Manne, 1961) we minimize $C(x)$, given by (4), with respect to $x$. For the stochastic model with linear expansion of demand we 
minimize (29) with respect to $y$ (Bean et al., 1992). For the stochastic model with geometric rate of growth of demand we put (Higle \& Corrado, 1992)

$$
y=h(x)=D_{0}[\exp (\alpha x)-1],
$$

into (29), and minimize (29) with respect to $x$. For the deterministic model with geometric rate of growth we apply the latter formulation, with $\sigma=0$.

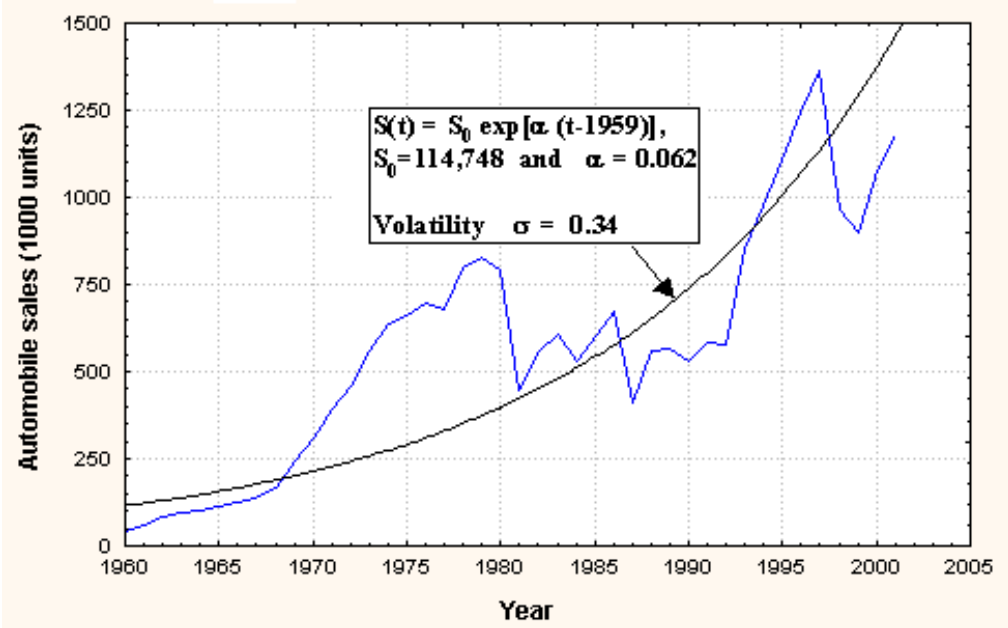

Figure 3 - Domestic sales of Brazilian manufactured automobiles (1960-2001).

The risk-free annual interest rate is $r_{f}=6 \%$, the risk premium, represented by $r_{M}-r_{f}$ in equation (57) is approximately equal to $10 \%$ in Brazil, and the value of $\beta$ for the project was assumed to be 1.2. Thus, equation (57) yields $r=18 \%$ for the project under analysis. The application of the capacity expansion models led to the results exhibited in Table 1 . The optimal capacity expansion interval, for the stochastic model with geometric rate of demand growth, is 4.7 years. Rounding off to $T=5$ years, the firm has to initially install a plant with capacity to manufacture $130,000+45,482=175,282$ cars per year, which will require an investment of 1,117.5 million US dollars (equation 62).

Table 1 - Optimal capacity expansion results.

\begin{tabular}{llccccc}
\hline \multicolumn{1}{c}{ Process } & $\begin{array}{c}\text { Demand } \\
\text { expansion }\end{array}$ & $\begin{array}{c}E[t] \\
\text { (years) }\end{array}$ & $\begin{array}{l}\text { Var }[t] \\
=\sigma_{t}^{2}\end{array}$ & $\begin{array}{c}\text { Demand, } \\
\text { first year } \\
\text { (cars/year) }\end{array}$ & $\begin{array}{c}\text { Opt. } \\
\text { capacity } \\
\text { expansion } \boldsymbol{x} \\
\text { (cars/year) }\end{array}$ & $\begin{array}{c}\text { Total } \\
\text { capacity to } \\
\text { install } \\
\text { (cars/year) }\end{array}$ \\
\hline Deterministic & Linear & 5.38 & 0.00 & 130,000 & 41,986 & 171,986 \\
Stochastic & Linear & 5.45 & 0.87 & 130,000 & 42,474 & 172,474 \\
Deterministic & Geometric & 5.21 & 0.00 & 130,000 & 47,732 & 177,732 \\
Stochastic & Geometric & 4,71 & 0.87 & 130,000 & 42,480 & 172,480 \\
\hline
\end{tabular}


Let us assume, for the sake of simplicity, that the industry will make one type of car only, whose price in the Brazilian market will be 7,275 dollars per unit. Assume further that the net margin obtained by the carmaker represents $16 \%$ of the revenues. Thus, the net margin is US\$ $1,180.00$ per car sold. The company has to invest $I_{0}=1,117.5$ million dollars at time zero. Let us assume, as in Manne (1961), Freidenfelds (1980,1981), and Bean et al. (1992), that the industry will continue to place additional facilities at equal-time intervals, as discussed in Section 2. Thus

$$
N P V=-I_{0}+\sum_{t=1}^{\infty} \frac{M_{t}}{(1+r)^{t}}-\sum_{t=1}^{\infty} \frac{I_{t}}{(1+r)^{t}},
$$

where $M_{t}$ is the net margin at year $t$, given by $M_{t}=1,180 \times D_{t}$, where $D_{t}$ is the demand at time $t$, and $I_{t}$ is the investment to add an additional capacity at time $t$. It can be shown that the geometric progressions in (64) are convergent. Putting $r=0.18$ in (64), one gets $N P V=-296.63$ million dollars, meaning the project is unfeasible when analyzed under the traditional $D C F$ method. On the other hand, the present value of the abandonment alternative under the $D C F$ approach, at time $T=5$, is

$$
N P V_{A B}=-I_{0}+\sum_{t=1}^{5} \frac{R_{t}-E_{t}}{(1+r)^{t}}+\frac{S V_{5}}{(1+r)^{5}},
$$

where $S V_{5}$ is the salvage value at $T=5$. We assume that the salvage value of the project is basically formed by its real estate value, and that all the machinery and equipment can be transferred to another facility, the firm incurring displacement costs only. The value $S V_{5}=0.75 I_{0}$ was assumed. Putting it into equation (65), one gets $N P V_{A B}=-188.74$ million dollars. Therefore, under the DCF approach, the firm would not undertake the project at all.

Now, let us analyze the problem with the real options approach. Suppose the car factory is ready to start operation, i.e. the project has passed all the planning, analysis and installation phases, being a real asset now. One possibility is to keep the project running after $T=5$, and consequently we have to analyze the cash flow of the project considering all future revenues and expenditures after that time horizon, which is given by

$$
S_{0}=\sum_{t=6}^{\infty} \frac{M_{t}}{(1+r)^{t}}-\sum_{t=5}^{\infty} \frac{I_{t}}{(1+r)^{t}}=496.11 \text { million dollars. }
$$

The other alternative is to abandon the project at $T=5$, leading to a discounted salvage value given by

$$
X_{0}=\sum_{t=1}^{5} \frac{R_{t}-E_{t}}{(1+r)^{t}}+\frac{S V_{t}}{(1+r)^{5}}=1,021.34 \text { million dollars. }
$$

In order to apply Margrabe's equation (53), it is necessary to choose an appropriate value for $\sigma$. The leading car manufacturers in Brazil are owned by international holding enterprises, and consequently their shares are not negotiated in the Brazilian stock market. Thus, the volatility of the project value-in-use cannot be estimated from the stock values of the firm. One approximation is to assume $\sigma_{S}$ to be approximately equal to the volatility of the local stock market index, which is approximately $20 \%$ (Ibovespa, São Paulo). The salvage value, 
on the other hand, is less volatile since is represented mostly by the real estate value. We assumed $\sigma_{X}=0.10$, with a low correlation coefficient $\rho=0.3$ between $X_{0}$ and $S_{0}$. Thus, relation (55) yields

$$
\sigma^{2}=\sigma_{X}^{2}-2 \sigma_{X} \sigma_{S} \rho+\sigma_{S}^{2}, \text { yielding } \sigma=0.195
$$

Putting $S_{0}=496.11 \times 10^{6}, \quad X_{0}=1,021.34, T=5$, and $\sigma=0.195$ into (53), one gets $f=531.43$ million dollars. This is the value of the put-call option (Margrabe, 1978) to be added to the project cash flow

$N P V^{\prime}=-I_{0}+\sum_{t=1}^{\infty} \frac{M_{t}}{(1+r)^{t}}-\sum_{t=1}^{\infty} \frac{I_{t}}{(1+r)^{t}}+f=-296.63+531.43=234.80$ million dollars

Thus, with the real-options approach, the project is economically feasible, since its net present value is positive. The introduction of the put-call option has added a significant value to the project. This is equivalent to say that, if market conditions turn out to be poor without any chance of recovery after a period of five years, the management can abandon the project and sell it for salvage value. Of course, this type of action is acceptable for large organizations that have a portfolio of investments in different international settings. The economic loss when abandoning one specific project is compensated by positive payoffs in other parts of the world.

\section{Conclusions}

The real options approach offers a wide spectrum of application possibilities. It can be combined with optimization models such as the capacity expansion modeling, as well as other kinds of formulations, being a small sample of what can be accomplished with this methodology. The application presented in this paper should be seen as a hypothetical example, since it is an extension to a classical capacity expansion problem, also hypothetical in nature. Apart from the unlikely infinite and ever-growing time horizon hypothesis present in the classical model, the plant may become technologically obsolete, and a finite horizon should be considered accordingly. Technology advances would also influence investment levels, production costs, market share, etc., thus requiring consequent changes in the variable values. Nevertheless, albeit simplified, the model brings some light on new ways of analyzing projects under volatile conditions.

Other authors have also investigated the abandonment-option problem associated with project life. For instance, we adopted a five-year time span to reanalyze the project in order to decide whether or not to abandon it. But, in fact, such a variable can also be subject to a real-options analysis. For instance, Song (2001) developed a stochastic real-options model to compute optimal exercise timing (first passage time). She demonstrated that there exists a threshold value for the reselling price of the asset bellow that the asset should be sold. A more comprehensive approach is due to Cohen \& Huchzermeier (1999, 2002). They state that global supply chain strategies should be viewed as compound options. They developed stochastic Dynamic Programming models focusing on dynamic investment strategies that include the option to wait, to abandon, to expand, to retract, to switch, and to improve (Cohen \& Huchzermeier, 1999). The objective of this kind of model is to optimize the supply-chain network integration with real options pricing methods. 


\section{Acknowledgements}

This research was partially supported by two grants from the National Council for Scientific and Technological Development (CNPq), Brazil, project numbers 500031/02-9 and 301144/91-5. The helpful comments of an anonymous referee of this journal are also gratefully acknowledged. In addition, we want to express our appreciation to the valuable advice of our colleague Professor Newton C.A. da Costa Jr.

\section{References}

(1) Amran, M. \& Kulatilaka, N. (1999). Real Options: Managing Strategic Investment in an Uncertain World. Harvard Business School Press, Boston, Massachusetts.

(2) ANFAVEA (2002). Statistical Yearbook of the Brazilian Automotive Industry. <http://www.anfavea.com.br>.

(3) Bean, J.C.; Higle, J.L. \& Smith, R.L. (1992). Capacity expansion under stochastic demand. Operations Research, 40, S210-S216.

(4) Bengtsson, J. (1999). The value of manufacturing flexibility: real options in practice. $3^{\text {rd }}$ Annual Real Options Conference, Leiden, Holland. <http://www.realoptions.org/> .

(5) Cambbell, J.H.; Lo, A.W. \& MacKinlay, A.C. (1997). The Econometrics of Finantial Markets. Princeton University Press, Princeton, New Jersey.

(6) Chow, G.C. \& Lawler, C.C. (2003). A time series analysis of the Shanghai and New York stock price indices. Annals of Economics and Finance, 4, 17-35.

(7) Cohen, M.A. \& Huchzermeier, A. (1999). Global supply chain management: a survey of research and applications. In: Quantitative Methods for Supply Chain Management [edited by S. Tayur et al.], Kluwer Academic, New York, 692-702.

(8) Cohen, M.A. \& Huchzermeier, A. (2002, May). Global supply chain network management under price/ exchange rate and demand uncertainty. <http://www.whu-koblenz.de/prod/>.

(9) Cohen, M.A. \& Lee, H.L (1989). Resource deployment analysis of global manufacturing and distribution network. Journal of Manufacturing Operations Management, 2, 81-104.

(10) Copeland, T. \& Antikarov, V. (2001). Real Options (in Portuguese). Editora Elsevier Campus, Rio de Janeiro, RJ.

(11) Dixit, A.K. \& Pindyck, R.S. (1994). Investment Under Uncertainty. Princeton University Press, Princeton, New Jersey.

(12) Edleson, M.E. (1999). Real options: valuing managerial flexibility. Publication 9-294-109, Harvard Business School, Cambridge, Mass.

(13) Feller, W. (1957). An Introduction to Probability Theory and its Applications. Wiley, New York, NY.

(14) Fong, C.O. \& Srinivasan, V. (1986). The multiregion dynamic capacity expansion problem: an improved heuristic. Management Science, 32, 1140-1152. 
(15) Freidenfelds, J. (1980). Capacity expansion when demand is a birth-death process. Operations Research, 28, 712-721.

(16) Freidenfelds, J. (1981). Capacity Expansion: Analysis of Simple Models with Applications. North-Holland, New York, NY.

(17) Higle, J.L. \& Corrado, C.J. (1992). Economic investment times for capacity expansion problems. European Journal of Operational Research, 59, 288-293.

(18) Hull, J. (1997). Options, Futures, and Other Derivative Securities. Prentice Hall, Englewood Cliffs, New Jersey.

(19) Jagannathan, R. \& McGrattan, E. (1995). The CAPM debate. Federal Reserve Bank of Minneapolis Quartely Review, 19(4), 2-17.

(20) Karlin, S. (1968). A First Course in Stochastic Processes. Academic Press, New York, NY.

(21) Kogut, B. \& Kulatilaka, N. (1994). Operating flexibility, global manufacturing, and the option value of a multinational network. Management Science, 40, 123-139.

(22) Li, S. \& Tirupati, D. (1994). Dynamic capacity expansion problem with multiple products: technology selection and timing of capacity addition. Operations Research, 42, 958-976.

(23) Lieberman, M.B. (1989). Capacity utilization: theoretical models and empirical tests. European Journal of Operational Research, 40, 155-168.

(24) Luehrman, T.A. (1995). Capital projects as real options: an introduction. Publication 9-295-074, Harvard Business School, Boston, Mass.

(25) Luehrman, T.A. (1998). Strategy as a portfolio of real options. Harvard Business Review, September-October.

(26) Luss, H. (1982). Operations research and capacity expansion problems: a survey. Operations Research, 30, 907-947.

(27) Manne, A.S. (1961). Capacity expansion and probabilistic growth. Econometrica, 29, 632-649.

(28) Margrabe, W. (1978). The value of an option to exchange one asset for another. The Journal of Finance, XXXIII(1), 177-186.

(29) Myers, S.C. \& Majd, S. (1990). Abandonment value and project life. In: Advances in Futures and Options Research [edited by F.J. Fabozzi], vol. 4, JAI Press, Greenwich.

(30) Novaes, A. G. (2000). Global Supply Chain Flexibility Under Risk: the Applichem Case. In: Building Competencies for International Manufacturing [edited by A. Fleury et al.], FEENG, Porto Alegre, RS, 209-217.

(31) Schnabel, J.A. (1992). Uncertainty and the abandonment option. The Engineering Economist, 37(2), 172-177.

(32) Song, J. (2001). Modelling real options: a first passage time approach. $5^{\text {th }}$ Annual Real Options Conference, Los Angeles, CA. <http://www.realoptions.org/>. 
(33) Souza, J.C. (1996). Sizing, Location and Staging of Emergency Service Facilities (in Portuguese). Doctoral Dissertation in Industrial Engineering, Federal University of Santa Catarina, Florianópolis, SC, Brazil.

(34) Srinivasan, T.N. (1967). Geometric rate of growth of demand. In: Investments for Capacity Expansion [edited by A.S. Manne], Allen \& Unwin, USA.

(35) Trigeorgis, L. (1996). Real options: Managerial flexibility and strategy in resource allocation. MIT Press, Cambridge, Mass.

(36) Verter, V. \& Dincer, M.C. (1995). Global manufacturing strategy. In: Facility Location [edited by Z. Drezner], Springer-Verlag, New York, NY, 263-282.

(37) Vidal, C.J. \& Goetschalckx, M. (1997). Strategic production-distribution models: a critical review with emphasis on global supply chain models. European Journal of Operational Research, 98, 1-18. 